\title{
A Thioredoxin of Sinorhizobium meliloti CE52G Is Required for Melanin Production and Symbiotic Nitrogen Fixation
}

\author{
Susana Castro-Sowinski, ${ }^{1,2}$ Ofra Matan, ${ }^{1}$ Paula Bonafede, ${ }^{1}$ and Yaacov Okon ${ }^{1}$ \\ ${ }^{1}$ Department of Plant Pathology and Microbiology and The Otto Warburg Minerva Center for Agricultural Biotechnology, \\ The Hebrew University of Jerusalem, Faculty of Agricultural, Food and Environmental Quality Sciences, P. O. Box 12, \\ 76100 Rehovot, Israel; ${ }^{2}$ Departamento de Bioquímica, Instituto Clemente Estable (IIBCE), y Laboratorio de Bioquímica, \\ Sección Biología Molecular y Celular, Facultad de Ciencias, Universidad de la República (UdelaR), Av. Italia 3318, \\ 11600 Montevideo, Uruguay
}

Submitted 2 January 2007. Accepted 12 March 2007.

\begin{abstract}
A miniTn5-induced mutant of a melanin-producing strain of Sinorhizobium meliloti (CE52G) that does not produce melanin was mapped to a gene identified as a probable thioredoxin gene. It was proved that the thiol-reducing activity of the mutant was affected. Addition to the growth medium of substrates that induce the production of melanin (L-tyrosine, guaiacol, orcinol) increased the thioredoxin-like $(\operatorname{tr} x L)$ mRNA level in the wild-type strain. The mutant strain was affected in the response to paraquatinduced oxidative stress, symbiotic nitrogen fixation, and both laccase and tyrosinase activities. The importance of thioredoxin in melanin production in bacteria, through the regulation of laccase or tyrosinase activities, or both, by the redox state of structural or catalytic SH groups, is discussed.
\end{abstract}

Melanin is a red to brownish pigment produced by animals, plants, fungi, and bacteria. It is synthesized by the oxidative polymerization of polyphenolic compounds (Henson et al. 1999) involving enzymes such as tyrosinase (Mercado-Blanco et al. 1993; Sanchez-Ferrer et al. 1995) or laccase (Thurston 1994). Tyrosinases have monophenol monooxygenase (EC 1.18.14.1) and $o$-diphenol:oxygen-oxidoreductase (EC 1.10.3.1) activities and laccases have $p$-diphenol:oxygen-oxidoreductase activity.

The ability to produce melanin has been linked to i) resistance to UV and visible light-irradiation (Hill 1992), ii) protection of cells against oxidizing and reducing conditions and antiviral activities (Montefiori and Zhou 1991), iii) resistance to attack by cell-wall enzymes (Kuo and Alexander 1967), and iv) enhanced survival and competitive abilities under environmental stresses (Bell and Wheeler 1986; Nosanchuk and Casadevall 2003). In addition, melanization is important for both plantand animal-pathogenic fungi because it reduces the susceptibility of melanized microbes to host defense mechanisms (Keller and Hohn 1997; Nosanchuk and Casadevall 2003; Salas et al. 1996; Tsai et al. 1998) and plays a role in lignin degradation (Hatakka 1998). Thus, it has been proposed that

Corresponding author: Su Castro-Sowinski; E-mail: scs@iibce.edu.uy; Telephone: +1 5982 487-1616; Fax: +1 5982 487-5548.

Nucleotide sequence data for $S$. meliloti CE52G, corresponding to the $\operatorname{tr} x L$ gene, is available in the GenBank database under accession number DQ436341. the interference with melanization is a potential strategy for antimicrobial drug and pesticide development (Nosanchuk and Casadevall 2003).

Endogenous production of melanin has been reported in bacterial species of the genera Aeromonas, Azospirillum, Azotobacter, Bacillus, Legionella, Micrococcus, Mycobacterium, Proteus, Pseudomonas, Rhizobium, Shewanella, Streptomyces, and Vibrio (Coyne and Al-Harthi 1992; Faure et al. 1994; Fuqua et al. 1991; Mercado-Blanco et al. 1993; Wang et al. 2000). Within soil bacteria, the melanin-producing strain Azospirillum lipoferum 4T does not survive well in unplanted soil requiring the rice rhizosphere to establish a stable population (Alexandre et al. 1996). Diamantidis and associates (2000) suggested that the ability of A. lipoferum to oxidize naturally occurring phenolic compounds derived from lignin metabolism could be related to the competitiveness of the bacteria in the rhizosphere of rice. Borthakur and associates (1987) proposed that melanin production in Rhizobium leguminosarum bv. phaseoli is involved in detoxification of phenolic compounds in nodules and roots of senescent common bean plants. Melanization was also proposed as an alternative mechanism for protection of nitrogenase from oxygen in the nitrogen-fixing bacteria Azotobacter (Shivprasad and Page 1989).

Melanin production by Rhizobium meliloti GR4 was linked to tyrosinase gene expression by Mercado-Blanco and associates (1993). In addition to tyrosinase, it has been suggested that laccase is involved in melanization of Sinorhizobium meliloti (Castro-Sowinski et al. 2002). Physiological conditions for laccase production and its purification and characterization have been reported (Castro-Sowinski et al. 2002; Rosconi et al. 2005).

Our long-term goal is to understand the mechanism of melanin production by a laccase- and tyrosinase-producing strain of $S$. meliloti. Here, we report that a thioredoxin-like miniTn5 mutant strain of $S$. meliloti $\mathrm{CE} 52 \mathrm{G}$ is defective in melanin production and in laccase and tyrosinase activities. The mutant strain is also affected in survival under paraquat-induced oxidative stress and in symbiotic nitrogen fixation on alfalfa plants. Thioredoxin and glutaredoxin are the major enzymes responsible for maintaining disulfide bonds in cytoplasmic proteins in a reduced state (Ritz and Beckwith 2001). Proteins that are capable of catalyzing protein disulfide bond formation are members of a large collection of thiol-disulfide oxidoreductases, many of them belonging to the thioredoxin superfamily (Kadokura et al. 2003). 


\section{RESULTS}

Isolation and mapping

of mutants deficient in melanin production.

To isolate $S$. meliloti mutants defective in melanin production, the melanin-producing wild-type strain CE52G was exposed to random mutagenesis with a miniTn5 $(\mathrm{Km})$ transposon. Within 2,000 transconjugants, a total of eight mutants unable to produce melanin were isolated. Southern blot analysis revealed a single insertion of the miniTn5 $(\mathrm{Km})$ in four of the mutants (data not shown), and the frequency of spontaneous mutations was determined as $0.2 \%$. The insertion site of the minitransposon was sequenced by inverse-polymerase chain reaction (iPCR) and was analyzed by BLASTn and BLASTx. In three of the four mutants, the insertions were located in genes for conserved hypothetical proteins with unknown function of $S$. meliloti 1021, named SMc01051, SMc03097, and SMc03833 (99 to $97 \%$ nucleotide identity).

The insertion in the fourth mutant (M43) mapped to a gene named trxA or AL591782, encoding a probable thioredoxin of S. meliloti 1021 ( $83 \%$ nucleotide identity). The entire ORF (open reading frame), now called $\operatorname{tr} x L$ (thioredoxin-like), and the up- and downstream regions were sequenced by primer walking. The genetic organization around the $\operatorname{tr} x L$ gene is shown in Figure 1A. Upstream to the trxL gene (accession number DQ436341), a putative promoter sequence (PtrxL) was identified. Downstream to the gene, an intergenic spacer and an ORF similar to a conserved hypothetical protein of Sinorhizobium medicae (ORF2) (accession number EAU04576) were found. The PtrxL putative promoter contains a Shine-Dalgarno sequence spaced $13 \mathrm{nt}$ from the start codon (Fig. 1B). Interestingly, a 57-bp sequence that showed $87 \%$ identity to a $R$. meliloti nitrogen-fixation promoter region (PORF2; accession number K01469; Better et al. 1983) was found between $\operatorname{trx} L$ and ORF2. The trxL highest similarity (BLASTx) was to $S$. meliloti 1021 (CAC41420; 68\% amino acid identity, 76\% similarity), followed by Agrobacterium tumefaciens (AAL4153; $63 \%$ amino acid identity, $74 \%$ similarity), Rhizobium etli (AAS67015; 61\% amino acid identity, 73\% similarity), and Mesorhizobium sp. (EAN07499; 60\% amino acid identity, $73 \%$ similarity), among others. Thioredoxins are small (about $12 \mathrm{kDa}$ ) and ubiquitous dithiol oxido-reductases that catalyze reduction of disulfides (Arner and Holmgren 2000), thus controlling the structure and activity of proteins that contain regulatory cysteines (Kumar et al. 2003). The CE52G TrxL predicted amino acid sequence, which includes the thioredoxin

A

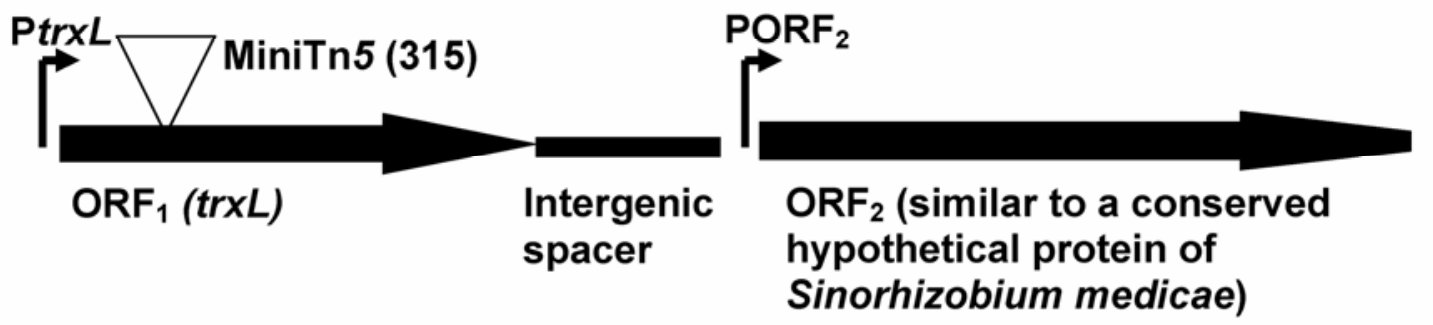

B

$100 \mathrm{bp}$

cacttgtgaggaggcgatgcgcggcctgatagagctgcaggagacttacaaagacct

1 atggctactgtgaaagtcgatacttccaatttctcggaagaagtt $\begin{array}{lllllllllllllll}M & A & T & V & K & V & D & T & S & N & F & S & E & E & V\end{array}$

46 ctgcagtcggccgaaccggtcatcgtcgacttctggaaaaacggg $\begin{array}{lllllllllllllll}L & Q & S & A & E & P & V & I & V & D & F & W & K & N & G\end{array}$

91 tgccagccgtgcgatatgattgtacccttcctcgaacaaatcgct $\begin{array}{lllllllllllllll}\mathbf{C} & \mathbf{Q} & \mathbf{P} & \mathbf{C} & \mathrm{D} & \mathrm{M} & \mathrm{I} & \mathrm{V} & \mathrm{P} & \mathrm{F} & \mathrm{L} & \mathrm{E} & \mathrm{Q} & \mathrm{I} & \mathrm{A}\end{array}$

136 accgagcttgctggcaaggtcaaggtcgtcaagatcaacaaggcc $\begin{array}{llllllllllllllllll}T & E & L & A & G & K & V & K & V & V & K & I & N & K & A\end{array}$

181 gaaaaccccgagctcgtggcgcggtatggcgtacgcggctaccca

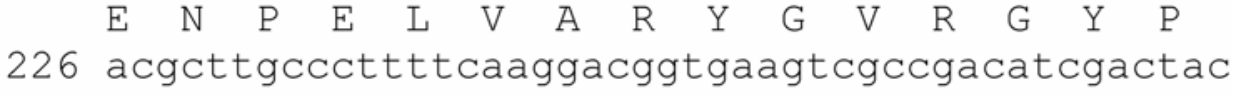
$\begin{array}{lllllllllllllll}T & L & A & L & F & K & D & G & E & V & A & D & I & D & Y\end{array}$

271 gactacgaacccggctcactccgctcctcgatttcggaggcgctg $\begin{array}{llllllllllllllllllllllll}D & Y & E & P & G & S & L & R & S & S & I & S & E & A & L\end{array}$

316 gcgagtctccggaacctgaacacagagtag 345 $\begin{array}{lllllllllll}A & S & L & R & N & L & N & T & E & *\end{array}$

Fig. 1. Sequence of and genetic organization around the $\operatorname{trx} L$ gene. A, Genetic organization around the trxL gene. Open reading frames $(\mathrm{ORF})$ are shown by solid arrows that indicate the direction of transcription; the trxL $(\mathrm{P} t r x L)$ and $\mathrm{ORF}_{2}\left(\mathrm{PORF}_{2}\right)$ promoters are represented by angled arrows; the site of the miniTn5 insertion (nucleotide 315) is shown by a triangle. B, $\operatorname{tr} x \mathrm{~L}$ nucleotide and predicted amino acid sequence. The promoter region is shown in italic letters (the Shine-Dalgarno sequence is bold and underlined). Start and stop codons are boldface. Typical CXXC motif is boxed boldfaced letters. 
CXXC conserved motif (Fig. 1B), was used to estimate the theoretical molecular weight (MW) $(12.569 \mathrm{kDa})$ and isoelectric point (pI) (4.57). From this point, we will name the gene as thioredoxin-like (trxL) and the theoretically translated thioldisulfide oxido-reductase activity protein as TrxL.

PCR analysis with primers based on conserved sequences upand downstream of the miniTn5 insertion and specific primers for S. meliloti $1021 \operatorname{tr} x A$ gene suggested the occurrence of two different copies of thioredoxin genes on the CE52G genome. The paralog trxL and trxA genes, showed 83 and $100 \%$ identity, respectively, to the $S$. meliloti $1021 \operatorname{trxA}$ gene.

To determine phylogenetic relationships between the CE52G TrxL and other representative proteins, multiple alignments among orthologous sequences and the paralog TrxA protein was performed using Clustal W. DsbA periplasmic disulfide bondformation proteins from different microorganisms were also included. The UPGMA (unweighted pair group method with arithmetic mean), neighbor-joining, and maximum-parsimony algorithms were employed to reconstruct phylogeny (Fig. 2). CE52G TrxL clustered to the cytoplasmic disulfide bond-formation proteins (thioredoxin) rather than periplasmic ones. The TrxL protein belongs to the thioredoxin-like protein superfamily containing the typical CXXC active motif.

\section{Biochemical characterization of the M43 mutant strain.}

In order to confirm that the M43 mutant strain was affected in the thiol-disulfide oxido-reductase activity, the thiol-reducing activities of the wild-type strain CE52G and the M43 mutant strain were measured. The mutant strain showed a thiolreducing activity fourfold lower than that observed for the wild-type strain (Table 1).

As tyrosinase and laccase are generally involved in melanin production, the activities of these enzymes were analyzed. Laccase activity was totally abolished and tyrosinase activity was reduced fourfold in the M43 mutant strain relative to the wild-type strain (Table 1). The abilities to produce melanin and the enzyme activities (thiol-reducing activity, laccase, and tyrosinase) were restored by complementation of the mutant strain by introduction of plasmid pML122::trxL, which carried the entire gene (Table 1).

\section{trx $L$ mRNA transcription under melanin production.}

Reverse transcription (RT)-PCR was used to assess transcription of the trxL gene. Total RNA from S. meliloti CE52G grown on tryptone yeast supplemented with $0.02 \mathrm{~g}$ of $\mathrm{CuSO}_{4}$ per liter (TY-Cu), TYT (TY-Cu with $0.60 \mathrm{~g}$ of L-tyrosine per liter), TYG (TY-Cu with $0.30 \mathrm{~g}$ of guaiacol per liter), and TYO (TY-Cu with $0.30 \mathrm{~g}$ of orcinol per liter) media (inducing melanin production) and TY (noninducing melanin production) was obtained and used for synthesis of cDNA that was employed as template for PCR. Figure 3A shows that a PCR product of similar size was amplified in all tested conditions. The bands were sliced from the gel, cloned into pGEM-T vector, and sequenced, confirming that they were the trxL gene. Cells that were grown in non-melanin inducing conditions showed lower amounts of trxL transcript in comparison to those that did produce melanin (Fig. 3A), suggesting an increase in trxL mRNA expression during pigment production. Transcripts of $16 \mathrm{~S}$ rRNA (900 bp) were used for normalization (Fig. 3B).

\section{Oxidative stress and survival assays.}

In order to analyze whether the $S$. meliloti CE52G TrxL protein is involved in oxidative stress, zone-of-growth inhibition and survival assays on wild type, complemented, and M43 mutant strains were performed in TYT medium. Clear zones of growth inhibition were observed when the disks were treated with $\mathrm{H}_{2} \mathrm{O}_{2}$, and turbid inhibition zones were formed around the disks when treated with paraquat. Statistical analysis of growth-inhibition zones did not show significant differences, but the survival assay did show significant differences $(P<$ 0.05 ) between wild type, complemented, and mutant strains when paraquat was used as oxidant. Table 2 shows a decreased resistance of the M43 mutant strain to paraquat but only a moderate effect was observed when $\mathrm{H}_{2} \mathrm{O}_{2}$ was used as oxidant.

Table 1. Biochemical characterization of Sinorhizobium meliloti CE52G, wild type, and M43 mutant strains

\begin{tabular}{lccc}
\hline Strain & Thiol-reducing $^{\mathbf{a}}$ & Laccase $^{\mathbf{b}}$ & Tyrosinase $^{\mathbf{c}}$ \\
\hline CE52G, wild type & $35.5 \pm 1.5$ & $14.0 \pm 2.2$ & $1.0 \pm 0.2$ \\
M43, miniTn5 mutant & $8.0 \pm 1.0$ & nd & $0.2 \pm 0.1$ \\
Complemented strain & $20.0 \pm 1.0$ & $8.0 \pm 2.0$ & $0.5 \pm 0.2$ \\
\hline
\end{tabular}

${ }^{\mathrm{a}}$ One unit of activity $=1 \mu \mathrm{mol}$ of reduced $5,5^{\prime}$-dithiobis 2-nitrobenzoic acid per min.

${ }^{\mathrm{b}}$ One unit of enzyme activity $=$ the amount of enzyme that catalyzed the oxidation of $1 \mu \mathrm{mol}$ of SGZ per min under standard assay conditions. nd = nondetectable.

${ }^{c}$ One unit of activity $=$ the amount of enzyme that catalyzed the oxidation of $1 \mathrm{nmol}$ of L-tyrosine per min under standard assay conditions.

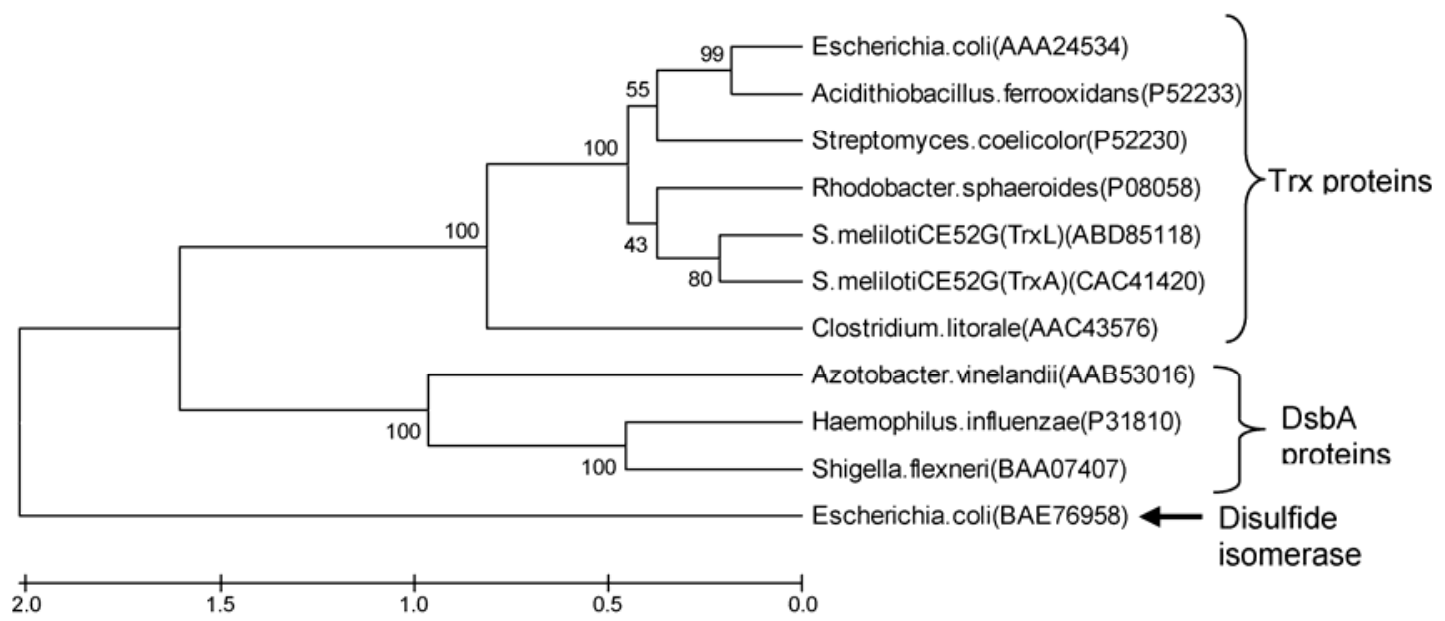

Fig. 2. Phylogenetic tree showing different thiol-disulfide oxido-reductase proteins (cytoplasmic Trx and periplasmic Dsb. A, Unweighted pair group method with arithmetic mean (UPGMA), maximum-parsimony, and neighbor-joining algorithms give similar topology, and therefore, only the UPGMA tree is shown. The tree was rooted using the protein sequence of the Escherichia coli disulfide isomerase. GenBank/EMBL accession numbers are shown in each branch of the tree. 
The wild type and complemented strains were resistant to 7 $\mathrm{mM}$ paraquat in both growth-inhibition zone and survival assays. It was observed that the melanin-inducing TYT medium renders more protection to paraquat to both wild type and complemented strains as compared with TY medium (data not shown).

Since melanin and melanin-like pigments are known to protect against ionizing radiation, we examined the survival of melanized (CE52G wild type) and nonmelanized (M43 mutant) strains after exposure to UV radiation. Experiments showed no significant differences between mutant, complemented, and wild-type strains. Viability decreased from $100 \%$

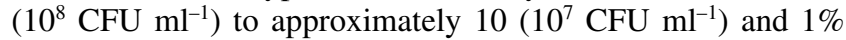
$\left(10^{6} \mathrm{CFU} \mathrm{ml}^{-1}\right)$ after 5- and 10-s exposure, respectively, in all strains. No survival was detected after $40 \mathrm{~s}$ of exposure to UV radiation.

\section{Plant experiments.}

The shoot dry matter of alfalfa plants inoculated with the CE52G wild type $(6.7 \pm 0.8 \mathrm{mg}$ per plant) showed significant differences $(P<0.05)$ when compared with plants inoculated with the M43 mutant $(4.8 \pm 0.1 \mathrm{mg}$ per plant) strain but showed no significant difference when compared with plants inoculated with the pML122::trxL complemented strain (5.5 \pm $0.5 \mathrm{mg}$ per plant). Plant controls, with and without nitrogen added, also showed significant difference $(9.0 \pm 0.4$ and $4.5 \pm$ $0.4 \mathrm{mg}$ of shoot dry weight per plant, respectively). No significant difference was detected between alfalfa plants inoculated with the M43 mutant strain and control plants without nitrogen.

Interestingly, all strains nodulated to the same extent (8 to 10 nodules per plant), and nodules occupation was, in all treatments, between $10^{7}$ and $10^{8} \mathrm{CFU}$ of rhizobia cells per gram of nodule. Microtome sections were observed by light microscopy, showing an apparently similar nodule structure and bacterial occupation of plant cells (not shown).

Competitiveness experiments for nodule occupation by coinoculating alfalfa plants with CE52G and M43 strains at different inoculum ratios showed around $50 \%$ nodule occupancy by each strain, suggesting that competitiveness was not affected in the mutant.

In contrast to plants inoculated with the wild-type strain or the complemented strain (acetylene reduction activity of 40 to 50 and 28 to $30 \mathrm{nmol}$ ethylene per h per plant, respectively), acetylene reduction could not be detected in plants inoculated with the mutant strain. No acetylene reduction activity was detected in noninoculated control plants. These results suggest that nitrogen fixation rather than infectivity was affected by the mutation of the $\operatorname{tr} x L$ gene.

\section{DISCUSSION}

Here, we report that a miniTn5-induced mutant of $S$. meliloti CE52G, affected in the thiol-disulfide oxido-reductase activity (thioredoxin-like protein), is defective in melanin production as well as in the laccase and tyrosinase activities. Thioredoxin is a major ubiquitous thiol-disulfide oxido-reductase responsible for maintaining many proteins in their reduced state. Electrons coming from NADPH via thioredoxin reductase reduce thioredoxin, which serves as an electron donor for enzymes such as ribonucleotide reductases, thioredoxin peroxidases, hydroperoxide reductase, superoxide dismutase, thiol peroxidase, methionine sulfoxide reductases, and catalase, among others (Arnér and Holmgren 2000; Kumar et al. 2003). In addition, thioredoxin interact with unfolded and denatured proteins in a manner similar to that of molecular chaperones that are involved in protein folding and protein renaturation after stress (Kern et al. 2003).

How might thioredoxin be related to either or both laccase or tyrosinase activities? Thioredoxin influences many cellular processes by affecting one or both protein folding or the activity of proteins by means of its thiol-redox control, as a hydrogen donor, or by formation of protein complexes (Arner and Holmgren 2000). Also glutathione (GSH) is a key player in keeping intracellular protein disulfides generally reduced. Changes in the thiol-disulfide redox status of proteins are important not only for the reactivation of enzymes and oxidative protein folding and stability but also for the control of protein function. Oxidation of critical cysteine residues can either activate or inactivate a given protein in physiologically significant reactions (Ritz and Beckwith 2001). Laccase and tyrosinase are copper-containing enzymes that catalyze the reduction of molecular oxygen by different electron donors, e.g., phenolic compounds. Laccases contain four copper ions essential for enzyme activity, coordinated in three different redox sites: type 1 , a site at which substrate oxidation takes place, and types 2

Table 2. Zone of inhibition and survival assays under oxidative stress

\begin{tabular}{lccc}
\hline Agent & $\begin{array}{c}\text { CE52G } \\
\text { (wild type) }\end{array}$ & $\begin{array}{c}\text { M43 } \\
\text { (mutant) }\end{array}$ & $\begin{array}{c}\text { Complemented } \\
\text { strain }\end{array}$ \\
\hline $\begin{array}{l}\text { Zone-of-growth inhibition assay } \\
\mathrm{H}_{2} \mathrm{O}_{2}(400 \mathrm{mM})\end{array}$ & $2.5 \pm 0.2$ & $3.0 \pm 0.2$ & $2.5 \pm 0.2$ \\
$\mathrm{H}_{2} \mathrm{O}_{2}(800 \mathrm{mM})$ & $3.5 \pm 0.2$ & $4.3 \pm 0.2$ & $3.4 \pm 0.2$ \\
Paraquat $(7 \mathrm{mM})$ & $\mathrm{nd}^{\mathrm{b}}$ & $1.0 \pm 0.3$ & $\mathrm{nd}$ \\
Paraquat $(70 \mathrm{mM})$ & $3.5 \pm 0.4$ & $4.1 \pm 0.1$ & $4.3 \pm 0.1$ \\
Survival $(\%)$ assay & & & \\
$\mathrm{H}_{2} \mathrm{O}_{2}(0.5 \mathrm{mM})$ & $70 \pm 10$ & $60 \pm 10$ & $70 \pm 10$ \\
$\mathrm{H}_{2} \mathrm{O}_{2}(1.0 \mathrm{mM})$ & $50 \pm 8$ & $50 \pm 7$ & $50 \pm 10$ \\
Paraquat $(7 \mathrm{mM})$ & $100 \pm 10$ & $20 \pm 6$ & $74 \pm 12$ \\
Paraquat $(70 \mathrm{mM})$ & $67 \pm 10$ & $15 \pm 7$ & $62 \pm 8$ \\
\hline
\end{tabular}

${ }^{a}$ Diameter of zone-of-growth inhibition in $\mathrm{cm}$.

${ }^{\mathrm{b}}$ nd means nondetectable.

${ }^{c}$ Numbers are given as percentage of viable cells after $1 \mathrm{~h}$ exposure to the oxidative agent at the indicated concentration. The amount of viable cells before the addition of the oxidative stress generating agents (approximately $10^{7} \mathrm{CFU}$ ) was considered $100 \%$ survival. Values are the average of three independent experiments.

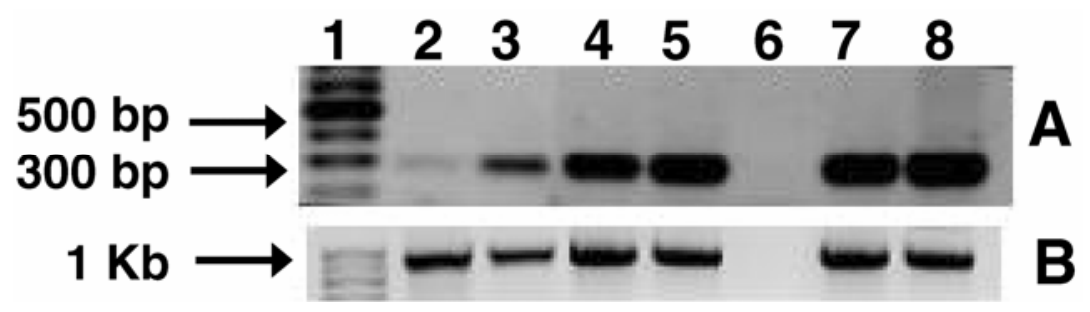

Fig. 3. $\operatorname{tr} x \boldsymbol{L}$ mRNA transcription under melanin production. A, Reverse transcription-polymerase chain reaction analysis and B, normalization. Line 1, DNA ladder (Promega Corp.); line 2, tryptone yeast (TY) medium (Beringer, 1974); line 3, TY supplemented with $0.02 \mathrm{~g}$ of CuSO 4 per liter (TY-Cu); line 4, TY$\mathrm{Cu}$ with $0.60 \mathrm{~g}$ of L-tyrosine per liter (TYT); line 5 , TY-Cu with $0.30 \mathrm{~g}$ of guaiacol per liter (TYG); line 6 , negative control; line 7 , Ty-Cu with $0.30 \mathrm{~g}$ of orcinol per liter (TYO); and line 8, CE52G DNA (positive control). 
and 3, trinuclear clusters at which reduction of oxygen takes place (Claus 2004). The type 1 site consists of two histidines, one cysteine, and one methionine (Nakamura and Go 2005). We think that the thiol-redox state of this cysteine, which is part of the active site, could be kept on its oxidized or reduced state by TrxL activity. Rosconi and associates (2005) showed that GSH and $\beta$-mercaptoethanol inhibit CE52G laccase activity, and Benathan and associates (1999) showed that the activity of human tyrosinase is regulated by cellular thiols. Thus, laccase and tyrosinase may be included within the proteins regulated by the redox state of structural or catalytic $\mathrm{SH}$ groups via a disulfide oxido-reduction system.

Frequently, laccase and tyrosinase mutants lead to a nonmelanogenic phenotype (Claus and Decker 2006). Also, a thioredoxin mutant of the photosynthetic bacterium Rhodobacter sphaeroides is affected in the production of photopigments (Pasternak et al. 1999). Similar findings were reported for regulation of chloroplast photosynthetic enzymes by Buchanan (1991). The activity of the human tyrosinase, the key enzyme of melanin biosynthesis, is influenced by the thioredoxin level and by superoxide radicals (Ruppitsch et al. 1998). In this report, we present data indicating that TrxL activity and bacterial melanin production are related.

To investigate the expression of the $\operatorname{tr} x L$ gene during melanin production, we analyzed the expression of the trx $L$ mRNA in the wild-type strain under both melanin and nonmelanin production by semiquantitative RT-PCR. Results showed that $\operatorname{tr} x \mathrm{~L}$ mRNA is up-regulated during pigment production, supporting the hypothesis that the TrxL protein is involved in melanin production by $S$. meliloti CE52G.

Results from survival rates and zone-inhibition assays confirmed that $S$. meliloti CE52G TrxL is involved in the defense against oxidative stress imposed by paraquat. However, its participation in the defense against $\mathrm{H}_{2} \mathrm{O}_{2}$ or UV radiation is still uncertain. The role of thioredoxin in oxidative stress has been previously reported in Rhodobacter capsulatus, Rhodobacter sphaeroides, Staphylococcus aureus, Helicobacter pylori, and Escherichia coli, among others (Comtois et al. 2003; Li et al. 2003a and b; Uziel et al. 2004). For example, Li and associates (2003b) showed that Rhodobacter sphaeroides TrxA is involved in defense against $\mathrm{H}_{2} \mathrm{O}_{2}$ but not in defense against paraquat. Herein, we report that a $S$. meliloti CE52G thiol-disulfide oxido-reductase is involved in defense against paraquat.

Alfalfa plant-inoculation assays under limited nitrogen showed that infectivity is not affected by the mutation in the $\operatorname{tr} x L$ gene. However, the plants were significantly less developed and showed no acetylene reduction activity when inoculated

Table 3. Strains and transposon used

\begin{tabular}{|c|c|c|}
\hline Strains & $\begin{array}{c}\text { Description and relevant } \\
\text { genotype }^{\mathrm{a}}\end{array}$ & Source or reference \\
\hline $\begin{array}{l}\text { S. meliloti } \\
\text { CE52G }\end{array}$ & $\begin{array}{l}\text { Wild type, } \mathrm{Nal}^{\mathrm{r}} \text {, melanin } \\
\text { producing strain, laccase and } \\
\text { tyrosinase activity }\end{array}$ & $\begin{array}{l}\text { Castro-Sowinski et al. } \\
2002\end{array}$ \\
\hline S. meliloti M43 & $\begin{array}{l}\text { Mutant strain, } \mathrm{Nal}^{\mathrm{r}} \mathrm{Km}^{\mathrm{r}} \\
\operatorname{tr} A A:: \operatorname{miniTn} 5(\mathrm{Km})\end{array}$ & This work \\
\hline $\begin{array}{r}\text { Escherichia } \\
\text { coli DH5 } \alpha\end{array}$ & $\begin{array}{l}\text { hsdR17 endA1 thi-1 gyrA96 } \\
\text { relA1 supE44 DlacU169 } \\
(\phi 80 \mathrm{~d} l a c Z \Delta \mathrm{M} 15)\end{array}$ & Sambrook et al. 1989 \\
\hline $\begin{array}{l}\text { E. coli } \mathrm{S} 17.1 \\
\mathrm{pUT} / \mathrm{miniTn} 5 \\
(\mathrm{Km} 2)\end{array}$ & $\begin{array}{l}\text { Strain for conjugative transfer } \\
\text { of the mobilisable suicide } \\
\text { plasmid pUT, carrying } \\
\text { miniTn } 5:: \mathrm{Km}, \mathrm{Km}^{\mathrm{r}}\end{array}$ & de Lorenzo et al. 1990 \\
\hline $\begin{array}{l}\text { E. coli DH5 } \alpha \\
\text { pML122 }\end{array}$ & $\begin{array}{l}\text { pML122 is a broad-host-range } \\
\text { expression vector; } \mathrm{Gm}^{\mathrm{r}}\end{array}$ & Labes et al. 1990 \\
\hline
\end{tabular}

${ }^{\mathrm{a}} \mathrm{Nal}^{\mathrm{r}}, \mathrm{Km}^{\mathrm{r}}$, and $\mathrm{Gm}^{\mathrm{r}}=$ resistant to nalidixic acid, kanamycin, and gentamycin, respectively. with the mutant strain as compared with plants inoculated with the wild type or complemented strain. The results suggest that TrxL protein is required for $S$. meliloti CE52G to show efficient nitrogen fixation in alfalfa. Vargas and associates (1994) reported that a $\operatorname{Tn} 5$-induced mutant, located in a $\operatorname{tr} x A$-like gene and defective in the maturation of all $c$-type cytochromes of Rhizobium leguminosarum bv. viciae, could form nodules on pea or vetch, but the nodules were not efficient in nitrogen fixation.

Nitrogen fixation is one of the most significant reactive oxygen species-producing processes (Buchanan and Balmer 2005). The regulation of nitrogen-fixation genes at the transcriptional level is exerted in response to the redox, fixed nitrogen, and carbon status via signaling mechanisms that control the activity of the NifA transcriptional activator. For example, the protein-protein interaction between the transcriptional activator or antiactivator, NifA/NifL, is modulated by redox changes, ligand binding, and interactions with the signal transduction protein GlnK (Dixon and Kahn 2004). In addition, thioredoxins are involved in redox-sensing signal transduction. Many transcription factors respond to oxidative agents by forming disulfide bonds through the antioxidant thioredoxin (Buchanan and Balmer 2005). Thus, it can be suggested that TrxL contributes as signal during nitrogen fixation by the modulation of the redox potential into the nodule.

Our data suggest that the transcription of the $S$. meliloti CE52G trxL gene is up-regulated by substrates that induce melanin production (L-tyrosine, guaiacol, orcinol) and that it is involved in laccase and tyrosinase activities. In addition, it is also shown that the $\operatorname{tr} x L$ mutant is affected in the response to oxidative stress imposed by paraquat and in the biological nitrogen-fixation process. Recently, it was reported that the $L A C 2$ laccase of the fungal pathogen Cryptococcus neoformans is involved in melanin production and nitric oxide stress response by the thioredoxin system-dependent thiol peroxidase Tsa 1 (Missall et al. 2005). The thiol-specific antioxidant Tsa 1 is a 2-Cys peroxiredoxin dependent on the thioredoxin system. Finally, our findings suggest that there is a relationship between melanin production, laccase, tyrosinase, and thioredoxin in the melanin-producing Sinorhizobium meliloti CE52G.

\section{MATERIALS AND METHODS}

\section{Bacterial strains, plasmids, and media.}

The bacterial strains used in this study are listed in Table 3. Escherichia coli and S. meliloti strains were grown in LuriaBertani broth, Lennox (Difco, Detroit) $\left(37^{\circ} \mathrm{C}\right)$, and TY (Beringer 1974) $\left(30^{\circ} \mathrm{C}\right)$ medium, respectively. When required, TY was supplemented with $0.02 \mathrm{~g}$ of $\mathrm{CuSO}_{4}$ and $0.60 \mathrm{~g}$ of L-tyrosine, $0.30 \mathrm{~g}$ of guaiacol, or $0.30 \mathrm{~g}$ of orcinol per liter. Bacterial strains were stored in $15 \%$ glycerol at $-80^{\circ} \mathrm{C}$.

\section{Transposon mutagenesis, screening of mutants deficient in melanin production, and complementation analysis.}

For miniTn5::Km2 mutagenesis, biparental mating was performed between the donor $E$. coli strain [S17.1 pUT/miniTn5 (Km2)] and the recipient $S$. meliloti CE52G. Cultures of donor and recipient strains were grown overnight, centrifuged (4 $\min , 5,000 \mathrm{rpm}, 4^{\circ} \mathrm{C}$ ), were washed in $0.9 \% \mathrm{NaCl}$, and were mixed at a ratio of $1: 10$. Aliquots $(200 \mu \mathrm{l})$ of the mixture were incubated in the center of petri dishes containing TY agar at $30^{\circ} \mathrm{C}$ overnight. Mating pairs were suspended in $1 \mathrm{ml}$ of $0.9 \%$ $\mathrm{NaCl}$ and were subjected to serial dilutions. Transconjugants were selected on TY medium containing $75 \mu \mathrm{g}$ of kanamycin and $30 \mu \mathrm{g}$ of nalidixic acid per milliliter. The numbers of donor and recipient cells were determined on appropriate growth 
media. Controls of the recipient strains were incubated under the same conditions, to determine the frequencies of spontaneous mutations. For selection of mutants impaired in melanin production, the ability to produce melanin on TYT, TYG, and TYO was analyzed on 2,000 transconjugants as described by Castro and associates (2000). Single insertion of the minitransposon was analyzed by Southern blot hybridization. Total DNA from wild type and mutant strains were isolated, digested with restriction enzymes, electrophoresed, and blotted onto MSI nylon transfer membranes (Roche Diagnostics. Basel. Switzerland) by standard methods (Sambrook et al. 1989). To label the specific miniTn5 probe with digoxigenin, DIG-dUTP nucleotide (Roche Applied Science) was incorporated during a linear PCR amplification. Prehybridization and hybridization were carried out at $68^{\circ} \mathrm{C}$, and detection was performed with the DIG luminescent detection kit (Roche Diagnostics).

Mutant complementation analysis was done by cloning the intact ORF1 of the trxL gene under the control of the constitutive neomycin promoter $(\mathrm{pNm})$ into the plasmid pML122 (Labes et al. 1990). Restriction sites were engineered into each primer ( $\mathrm{Xba \textrm {I }}$ and $\mathrm{Bam \textrm {HI }}$ in the forward and reverse primer, respectively) for the amplification of the intact ORF1. The PCR fragment was cloned into the XbaI-BamHI sites of the broad host range plasmid pML122, downstream of the constitutive pNm promotor. The resulting pML122::trxL plasmid was then introduced into the conjugative $E$. coli $\mathrm{S} 17.1$ strain and was used for biparental mating with M43 strain.

\section{iPCR.}

iPCR (Martín and Mohn 1999) was used to identify the site of transposon insertion. Genomic DNA was independently digested with SalI, SphI, PstI, NcoI, XbaI, XhoI, BamHI, and $K p n I$. The restriction enzymes were then inactivated $\left(65^{\circ} \mathrm{C}, 20\right.$ min), and aliquots were incubated with T4 DNA ligase overnight at room temperature. The resulting self-ligated DNA was directly used as template for traditional PCR, using outward primers based on the miniTn5 sequence (Ovadis et al. 2004). PCR reactions $(50 \mu \mathrm{l})$ contained $4 \mu \mathrm{l}$ of self-ligated genomic DNA or $30 \mathrm{ng}$ of native genomic DNA, 10 pmol of each primer, $0.2 \mathrm{mM}$ of each dNTP, $1 \mathrm{U}$ Taq DNA polymerase (Promega, Madison, WI, U.S.A.), $3 \mathrm{mM} \mathrm{MgCl}_{2}$, and Q-solution (Life Technologies, Gaithersburg, MD, U.S.A.). The thermocycler was programmed as follows: $5 \mathrm{~min}$ at $94^{\circ} \mathrm{C}$; followed by 30 cycles of $1 \mathrm{~min}$ at $94^{\circ} \mathrm{C}, 1 \mathrm{~min}$ at $56^{\circ} \mathrm{C}$, and $5 \mathrm{~min}$ at $72^{\circ} \mathrm{C}$; ending with $5 \mathrm{~min}$ at $72^{\circ} \mathrm{C}$. PCR products were cloned into pGEM-T easy vector (Promega) according to manufacturer's instructions, were transformed into $E$. coli DH5 $\alpha$ cells, and were sequenced.

\section{Sequence analysis, multiple alignments, and construction of phylogenetic trees.}

Sequences were analyzed by BLASTn and BLASTx using both the National Center for Biotechnology Information (NCBI) and European Bioinformatics Institute (EBI) websites. Parameters were chosen by default. ORFs and promoters were identified by the NCBI ORF Finder and Berkeley Drosophila Genome Project Promoter Finder, looking on prokaryotic sequences with a score cut-off of 0.8. Theoretical pI and MW were determined using ExPASy. Multiple alignments of fully characterized cytoplasmic and periplasmic disulfide bond formation proteins were performed using the CLUSTAL W program (Thompson et al. 1994). Phylogenetic trees were inferred with UPGMA (JTT model), maximum-parsimony (heuristic search factor 2), and neighbor-joining (JTT model) analyses, using MEGA3.1 (Kumar et al. 2004). Confidence in topologies was assessed using bootstrapping (1,000 replicates).
RNA extraction and RT-PCR analysis.

$S$. meliloti CE52G was inoculated in TY medium (nonmelanin production) and in melanin production-inducing media (TYT, TYG, and TYO) and was grown until early stationary phase. Total RNA was extracted using the MasterPure RNA purification kit (Epicentre, Madison, WI, U.S.A.) according to manufacturer's instructions. Absence of DNA was analyzed by electrophoresis on $1 \%$ agarose gels and by PCR, using the RNA extraction as template and primers for trxL amplification. Total RNA concentration was determined at 260 $\mathrm{nm}$, and transcripts of $16 \mathrm{~S}$ rRNA were used as control and for normalization of the expression of $\operatorname{tr} x L$ amplicon. RNA extraction was reverse-transcribed to cDNA using the ImProm-II reverse transcription system (Promega) and the reverse primer for trxL gene, following manufacturer's instructions. PCR amplification using Promega Taq polymerase was carried out using the reverse-transcribed cDNA as template, $10 \mathrm{pmol}$ each primer, $3 \mathrm{mM} \mathrm{MgCl}_{2}$, and $0.2 \mathrm{mM}$ of each dNTP. The thermocycler was programmed as follows: $5 \mathrm{~min}$ at $94^{\circ} \mathrm{C}$, followed by 26 cycles of $1 \mathrm{~min}$ at $94^{\circ} \mathrm{C}, 1 \mathrm{~min}$ at $50^{\circ} \mathrm{C}$, and $1 \mathrm{~min}$ at $72^{\circ} \mathrm{C}$, followed by $5 \mathrm{~min}$ at $72^{\circ} \mathrm{C}$.

\section{Biochemical characterization.}

Cells were grown in TYT medium until stationary phase, were harvested by centrifugation $\left(10,000 \times g, 15 \mathrm{~min}\right.$, at $\left.4^{\circ} \mathrm{C}\right)$, and were washed and suspended with $50 \mathrm{mM}$ phosphate buffer $(\mathrm{pH}$ 7.2). The suspension was sonicated in an icebox for 12 min, at a relative power output of 7 and a 0.5 duty period, and was then centrifuged at $39,000 \times g$ for $30 \mathrm{~min}$ at $4^{\circ} \mathrm{C}$, and the supernatant (crude extract) was stored at $-20^{\circ} \mathrm{C}$. The measurement of the thiol-reducing activity was performed by analyzing the timecourse reaction between $5,5^{\prime}$-dithiobis 2 -nitrobenzoic acid $\left(13,600 \mathrm{M}^{-1} \mathrm{~cm}^{-1}\right)$ and the crude extract at $412 \mathrm{~nm}$ as described by Pasternak and associates (1999). Laccase and tyrosinase activities were determined by measuring the oxidation of syringaldazine $\left(65,000 \mathrm{M}^{-1} \mathrm{~cm}^{-1}\right)$ and L-tyrosine $\left(3,600 \mathrm{M}^{-1}\right.$ $\left.\mathrm{cm}^{-1}\right)$ at 525 and $475 \mathrm{~nm}$, respectively, as described by Rosconi and associates (2005) and Castro-Sowinski and associates (2002). Protein concentration was determined using the Bradford reagent (BioRad, Hercules, CA, U.S.A.) and bovine serum albumin as standard.

\section{Determination of survival rates and zone-of-inhibition assays.}

Cultures of wild type and mutant strains were grown on TYT until stationary phase, and were afterwards diluted with TYT to an optical density of 0.1 at $540 \mathrm{~nm}$. The oxidative stress agents were then added at indicated concentrations for $1 \mathrm{~h}$, and serial dilutions were plated. Survival of $100 \%$ was defined as the number of viable cells immediately before the addition of the oxidative agents. Paraquat and $\mathrm{H}_{2} \mathrm{O}_{2}$ were used as superoxide- and hydroxyl radical-generating compounds, respectively. Resistance to UV radiation was tested by placing $20 \mathrm{ml}$ of cell suspension (at approximately $10^{8} \mathrm{CFU} \mathrm{ml}^{-1}$ ) in $90-\mathrm{cm}$ plastic petri dishes and exposing them to short-wave UV radiation $(254 \mathrm{~nm})$, using a VL-6LC UV lamp (Vilber-Lourmat, Cedex, France) for $60 \mathrm{~s}$. Bacterial viability was determined every $5 \mathrm{~s}$.

For zone of growth-inhibition assays, cells were grown on TY until stationary phase, and $10^{7} \mathrm{CFU}$ were plated on TYT agar. Filter paper disks $(5 \mathrm{~mm})$ saturated with $10 \mu \mathrm{l}$ of different oxidative agents were placed on the plates. The plates were incubated for 2 days at $30^{\circ} \mathrm{C}$, and the diameter of the zone of growth inhibition was measured in various directions, in order to obtain an average value for each experiment.

All assays were performed three times with three replicates each. Bacterial survival and diameter of the zone of growth inhibition of both wild type and M43 mutant strains under 
nonoxidative and oxidative stress conditions were compared using ANOVA-1 (analysis of variance 1).

\section{Plant assay (shoot dry weight, acetylene-ethylene reduction, occupancy, and competitiveness).}

Seeds of Medicago sativa cv. Gilboa were surface-sterilized by rinsing for $10 \mathrm{~min}$ on absolute ethanol followed by washings with water, were germinated in $0.8 \%$ agar water, were transferred to $25 \times 200-\mathrm{mm}$ tubes containing $10 \mathrm{ml}$ of Jensen medium (Vincent 1970), and were inoculated with $10^{4} \mathrm{CFU}$ per seed. Controls with addition of nitrogen $\left(0.05 \% \mathrm{KNO}_{3}\right.$, final concentration) and without a nitrogen source were run. The experiment was repeated twice, using 20 plants per treatment. Plants were incubated in a growth chamber $(18 \mathrm{~h}$ light, $6 \mathrm{~h}$ dark; 18 to $20^{\circ} \mathrm{C}$ ) for 42 days. Then, plants were collected and their shoot dry weight was measured after $24 \mathrm{~h}$ of drying at $80^{\circ} \mathrm{C}$ until constant weight. Statistical analysis was done using ANOVA-1, with a least significant difference of 0.05 .

Nitrogenase activity was assessed by the acetylene reduction assay. Acetylene was injected into sealed $60-\mathrm{ml}$ tubes containing 6-week-old plants, to a final concentration of $10 \%$ (vol/vol) by replacement of an identical volume of air. Reduction of acetylene to ethylene was measured by flame ionization gas chromatography (Carlo Erba, Milano, Italy) after 30 and $60 \mathrm{~min}$ of incubation at $30^{\circ} \mathrm{C}$.

Tubes containing $10 \mathrm{ml}$ of Jensen medium and two alfalfa germinated seeds were coinoculated with CE52G wild type and M43 mutant strains at different ratios (1:9, 5:5, and 9:1), finally reaching $10^{4} \mathrm{CFU}$ per seed. Nodulation occupancy and competitiveness assay were performed using both melanin production and antibiotic resistance as markers (Castro et al. 2000).

\section{ACKNOWLEDGMENTS}

We thank S. Burdman, E. Jurketvich, and A. Behar for valuable suggestions, L. Chernin for providing primers for iPCR. A Valazzi-Pikovsky Fellowships Fund and Lady Davis Trust Fellowships supported the work of S. Castro-Sowinski at The Hebrew University of Jerusalem. Comision Sectorial de Investigacion Cieutifica-Uruguay supported travel expenses of S. Castro-Sowinski.

\section{LITERATURE CITED}

Alexandre, G., Jacoud, C., Faure, D., and Bally, R. 1996. Population dynamics of a motile and a non-motile Azospirillum lipoferum strain during rice colonization and motility variation in the rhizosphere. FEMS (Fed. Eur. Microbiol. Soc.) Microbiol. Ecol. 19:271-278.

Arnér, E. S., and Holmgren, A. 2000. Physiological functions of thioredoxin and thioredoxin reductase. Eur. J. Biochem. 267:6102-6109.

Bell, A. A., and Wheeler, M. H. 1986. Biosynthesis and functions of fungal melanins. Annu. Rev. Phytopathol. 24:411-451.

Benathan, M., Virador, V., Furumura, M., Kobayashi, N., Panizzon, R. G., and Hearing, V. J. 1999. Co-regulation of melanin precursors and tyrosinase in human pigment cells: Roles of cysteine and glutathione. Cell Mol. Biol. 45:981-990.

Better, M., Lewis, B., Corbin, D., Ditta, G., and Helinski, D. R. 1983. Structural relationships among Rhizobium meliloti symbiotic promoters. Cell 35:479-485.

Beringer, J. E. 1974. R factor transfer in Rhizobium leguminosarum. J. Gen. Microbiol. 84:188-198.

Borthakur, D., Lamb, J. W., and Johnston, A. W. B. 1987. Identification of two classes of Rhizobium phaseoli genes required for melanin synthesis, one of which is required for nitrogen fixation and activates the transcription of the other. Mol. Genet. Genome 207:155-160.

Buchanan, B. B. 1991. Regulation of $\mathrm{CO}_{2}$ assimilation in oxygenic photosynthesis: The ferredoxin/thioredoxin system. Perspective on its discovery, present status, and future development. Arch. Biochem. Biophys. 288:1-9.

Buchanan B. B., and Balmer, Y. 2005. Redox regulation: A broadening horizon. Annu. Rev. Plant Biol. 56:187-220.

Castro, S., Carrera, I., and Martinez-Drets, G. 2000. Methods to evaluate nodulation competitiveness between Sinorhizobium meliloti strains using melanin production as a marker. J. Microbiol. Meth. 41:173-177.

Castro-Sowinski, S., Martinez-Drets, G., and Okon, Y. 2002. Laccase activity in melanin-producing strains of Sinorhizobium meliloti. FEMS (Fed. Eur. Microbiol. Soc.) Microbiol. Lett. 209:119-125.

Claus, H. 2004. Laccases: Structure reactions, distribution. Micron 35:9396.

Claus, H., and Decker, H. 2006. Bacterial tyrosinases. Syst. Appl. Microbiol. 29:3-14

Comtois, S., Gidley, M. D., and Kelly, D. J. 2003. Role of the thioredoxin system and the thiol-peroxidases Tpx and Bcp in mediating resistance to oxidative and nitrosative stress in Helicobacter pylori. Microbiol. 149:121-129.

Coyne, V., and Al-Harthi, L. 1992. Induction of melanin biosynthesis in Vibrio cholerae. Appl. Enrivon. Microbiol. 58:2861-2865.

de Lorenzo, V., Herrero, M., Jakubzik, U., and Timmis, K. N. 1990. MiniTn5 transposon derivatives for insertion mutagenesis, promoter probing, and chromosomal insertion of cloned DNA in gram-negative eubacteria. J. Bacteriol. 172:6568-6572.

Diamantidis, G., Effosse, A., Potier, P., and Bally, R. 2000. Purification and characterization of the first bacterial laccase in the rhizospheric bacterium Azospirillum lipoferum. Soil Biol. Biochem. 1:919-927.

Dixon, R., and Kahn, D. 2004. Genetic regulation of biological nitrogen fixation. Nat. Rev. Microbiol. 2:621-631.

Faure, D., Bouillant, M. L., and Bally, R. 1994. Isolation of Azospirillum lipoferum 4T Tn5 mutants affected in melanization and laccase activity. Appl. Environ. Microbiol. 60:3413-3415.

Fuqua, W. C., Coyne, V. E., Stein, D.C., Lin, C. M., and Weiner, R. M. 1991. Characterization of melA: A gene encoding melanin biosynthesis from the marine bacterium Shewanella colwelliana. Gene 109:131-136.

Hatakka, A. 1998. Lignin-modifying enzymes from select while-rot fungi: Production and role in lignin degradation. FEMS (Fed. Eur. Microbiol. Soc.) Microbiol. Rev. 13:125-135.

Henson, J. M., Butler, M. J., and Day, A. W. 1999. The dark side of the mycelium: Melanins of phytopathogenic fungi. Annu. Rev. Phytopathol. 37:447-471.

Hill, H. Z. 1992. The function of melanin or six blind people examine an elephant. Bio Essays 14:49-56

Kadokura, H., Katzen, F., and Beckwith, J. 2003. Protein disulfide bond formation in prokaryotes. Annu. Rev. Biochem. 72:111-135

Keller, N. P., and Hohn, T. M. 1997. Metabolic pathway gene clusters in filamentous fungi. Fungal Genet. Biol. 21:17-29.

Kern, R., Malki, A., Holmgren, A., and Richarme, G. 2003. Chaperone properties of Escherichia coli thioredoxin and thioredoxin reductase. Biochem. J. 371:965-972.

Kumar, J. K., Tabor, S., and Richardson, C. C. 2003. Proteomic analysis of thioredoxin-targeted proteins in Escherichia coli. Proc. Natl. Acad. Sci. U.S.A. 101:3759-3764.

Kumar, S., Tamura, K., and Nei, M. 2004. MEGA3: Integrated software for molecular evolutionary genetics analysis and sequence alignment. Brief Bioinformat. 5:150-163.

Kuo, M. J., and Alexander, M. 1967. Inhibition of the lysis of fungi by melanins. J. Bacteriol. 94:624-629.

Labes, M., Pühler, A., and Simon, R. 1990. A new family of RSF1010derived expression and $l a c$-fusion broad-host-range vectors for gramnegative bacteria. Gene 89:37-46.

Li, K. Härtig, E., and Klug, G. 2003a. Thioredoxin 2 is involved in oxidative stress defence and redox-dependent expression of photosynthesis genes in Rhodobacter capsulatus. Microbiol. 149:419-430.

Li, K., Pasternak, C., and Klug, G. 2003b. Expression of the trxA gene for thioredoxin 1 in Rhodobacter sphaeroides during oxidative stress. Arch. Microbiol. 180:484-489.

Martin, V. J. J., and Mohn, W. W. 1999. An alternative inverse PCR (IPCR) method to amplify DNA sequences flanking T5 transposon insertions. J. Microbiol. Meth. 35:163-166.

Mercado-Blanco, J., Garcia, F., Fernández-Lopez, M., and Olivares, J. 1993. Melanin production by Rhizobium meliloti GR4 is linked to nonsymbiotic plasmid pRmeGR4b: Cloning, sequencing and expression of the tyrosinase gene mepA. J. Bacteriol. 175:5403-5410.

Missall, T. A., Moran, J. M., Corbett, J. A., and Lodge, J. K. 2005. Distinct stress responses of two functional laccases in Cryptococcus neoformans are revealed in the absence of the thiol-specific antioxidant Tsa 1 . Eukaryot. Cell 4:202-208.

Montefiori, D. C., and Zhou, J. 1991. Selective antiviral activity of synthetic soluble L-tyrosine and L-dopa melanins against human immunodeficiency virus in vitro. Antiviral Res. 15, 11-25.

Nakamura, K., and Go, N. 2005. Function and molecular evolution of multicopper blue proteins. Cell Mol. Life Sci. 18:2050-2066.

Nosanchuk, J. D., and Casadevall, A. 2003. The contribution of melanin to microbial pathogenesis. Cell Microbiol. 5:203-223. 
Ovadis, M., Liu, X., Gavriel, S., Ismailov, Z., Chet, I., and Chernin, L. 2004. The global regulator genes from biocontrol strain Serratia plymuthica IC1270: Cloning, sequencing, and functional studies. J. Bacteriol.186:4986-4993.

Pasternak, C., Haberzetti, K., and Klug, G. 1999. Thioredoxin is involved in oxygen-regulated formation of the photosynthetic apparatus of Rhodobacter sphaeroides. J. Bacteriol. 181:100-106.

Ritz, D., and Beckwith, J. 2001. Roles of thiol-redox pathways in bacteria. Annu. Rev. Microbiol. 55:21-48.

Rosconi, F., Franco-Fraguas, L., Martínez-Drets, G., and Castro-Sowinski, S. 2005. Purification and characterization of a periplasmic laccase produced by Sinorhizobium meliloti. Enz. Microb. Technol. 36:800-807.

Ruppitsch, W., Meisslitzer, C., Hirsch-Kauffmann, M., and Schweiger, M. 1998. Overexpression of thioredoxin in Fanconi anemia fibroblasts prevents the cytotoxic and DNA damaging effect of mitomycin $\mathrm{C}$ and diepoxybutane. FEBS (Fed. Eur. Biochem. Soc.) Lett. 422:99-102.

Salas, S. D., Bennet, J. E., Kwon-Chung, K. J., Perfect, J. R., and Williamson, P. R. 1996. Effect of the laccase gene CNLAC1, on virulence of Cryptococcus neoformans. J. Exp. Med. 184:377-386.

Sambrook, J., Fritsch, E. F., and Maniatis, T. 1989. Molecular Cloning: A Laboratory Manual, 2nd ed. Cold Spring Harbor Laboratory, Cold Spring Harbor, NY, U.S.A.

Sanchez-Ferrer, A., Rodriguez-Lopez, J. N., Garcia-Canovas, F., and Garcia-Carmona, F. 1995. Tyrosinase: A comprehensive review of its mechanism. Biochim. Biophys. Acta 1247:1-11.

Shivprasad, S., and Page, W. J. 1989. Catechol formation and melanization by $\mathrm{Na}^{+}$-dependent Azotobacter chroococcum: A protective mechanism for aeroadaptation? Appl. Environ. Microbiol. 55:1811-1817.

Thompson, J. D., Higgins, D. G., and Gibson, T. J. 1994. CLUSTAL W: Improving the sensitivity of progressive multiple sequence alignment through sequence weighting, position-specific gap penalties and weight matrix choice. Nucl. Acids Res. 22:4673-4680.

Thurston C. F. 1994. The structure and function of fungal laccase. Microbiol 140:19-26.

Tsai, H. F., Chang, Y. C., Washburn, R. G., Wheeler, M. H., and KwonChang, K. J. 1998. The developmentally regulated alb 1 gene of Aspergillus fumigatus: Its role in modulation of conidial morphology and virulence. J. Bacteriol. 180:3031-3038.

Uziel, O., Borovok, I., Schreiber, R., Cohen, C., and Aharonowitz, Y. 2004. Transcriptional regulation of the Staphylococcus aureus thioredoxin and thioredoxin reductasa genes in response to oxygen and disulfide stress. J. Bacteriol. 186:326-334.

Vargas, C., Wu, G., Davies, A. E., and Downie, J. A. 1994. Identification of gene encoding a thioredoxin-like product necessary for cytochrome c biosynthesis and symbiotic nitrogen fixation in Rhizobium leguminosarum. J. Bacteriol. 176:4117-4123.

Vincent, J. M. 1970. A Manual for Practical Study of the Root-Nodule Bacteria. Page 77 in: IBP Handbook 115, Blackwell Scientific Publications, Oxford, Edinburgh.

Wang, G., Aazaz, A., Peng, Z., and Shen, P. 2000. Cloning and overexpression of a tyrosinase gene mel from Pseudomonas maltophila. FEMS (Fed. Eur. Microbiol. Soc.) Microbiol. Lett. 185:23-27.

\section{AUTHOR-RECOMMENDED INTERNET RESOURCES}

Berkeley Drosophila Genome Project Promoter Finder website: www.fruitfly.org/seq_tools/promoter.html

EBI website: www.ebi.ac.uk/blast2

ExPASy compute pI/Mw tool: us.expasy.org/tools/pi_tool.html NCBI website: www.ncbi.nlm.nih.gov

NCBI ORF Finder: www.ncbi.nlm.nih.gov/gorf/gorf.html 